\title{
Social Media Effects and Self- Harm Behaviors Among Young People: Theoretical and Methodological Challenges
}

\author{
Argyro Kefala ${ }^{1}$
}

\begin{abstract}
The pervasiveness of social media in the lives of the young has prompted a growing number of studies investigating their effects on online and offline behaviors, especially when it comes to risk or self -harm behaviors. The examination of self- harm behaviors both suicidal and nonsuicidal is grounded primarily in psychological and medical research but the increase in the number of adolescents who self- harm, in the last few years, expanded research into the use of social media. While there were both positive and negative accounts of the relationship of social media use to self- harm, this paper addresses the issue from a communication perspective. The main argument of this paper is that social media are complex interactive, multimodal and multidirectional environments and user created cultures that cannot be understood through traditional theories of media effects or simply in quantitative terms of uses and gratifications. Drawing from contemporary studies on media effects and social media affordances, this is an attempt to map the theoretical and methodological challenges in an effort to lay the ground for an enhanced understanding of social media as mediators in self-harming behaviors. A review of current studies in this field reconfirms the conditional and indirect character of media effects identifying at the same time the limitations and gaps in the examination of a complex behavior as it relates to multimodal "self- mass communication" (Castells, 2009) that leads to new forms of "socialized communication". Further research on social media affordances and their effects on the cognitive and social-emotional development of young people will provide a better analytical framework not only for the assessment of self-harm but also for using social media to mitigate negative behaviors.
\end{abstract}

Keywords: Self-harm, Social media, Adolescents, Media effects, Affordances

\footnotetext{
1 Associate Professor, Graduate Program Coordinator- MA in Strategic Communication \& Public Relations, Communication Department, Deree-The American College of Greece, email: argykefala@acg.edu
} 


\section{INTRODUCTION}

In recent years there have been reports showing that self-harm, involving different forms of selfinjury as a way of coping with negative emotions, has become a major public health issue, affecting primarily the young. Several studies indicate that incidents of self-harm have been increasing, especially amongst girls. For example, in the UK, recent studies provided documentation of the rising rate of common mental disorders, suicide and non- suicidal selfharm among young adults (Morgan et al, 2017; McManus et al, 2019, 2020; Bould et al, 2019), pointing to an alarming trend. There is also growing evidence that social technologies may have a negative impact on the overall mental wellbeing of the young (Kelly et al., 2019; RSPH, 2019; Shakya \& Christakis, 2017).

The Royal Society for Public Health (UK) report (2017) on "Social media and young people's mental health and wellbeing" described social media as "more addictive than cigarettes and alcohol" stressing that social media use is linked with increased rates of anxiety, depression, and poor sleep. It is interesting to note that two key recommendations of the report stress the necessity for professionals who engage with young people to have a social media training as well as the need for additional research to be carried out into the effects of social media on young people's mental health. The pervasiveness of social media in the lives of young people has prompted a growing number of studies investigating their effects on online and offline behaviors, as social media provide new multidirectional spaces for interpersonal and intrapersonal communication, information dissemination, and community building (Valkenburg, 2017). Although there has been a long "media effects" tradition in communication studies, a literature review has shown that communication scholars have minimally engaged with research on social media and mental disorders due to the special nature and complexity of those behaviors. On the other hand, research in the medical community was conducted from a psychological perspective that has not considered key theories and concepts from the field of digital communication that might have been useful in the analysis of a multifaceted problem. Several studies have been able to shed light on negative behaviors; however, they have provided partial and often conflicting views as to the role of social media. (Livingstone et al., 2018; Dyson et al, 2016). It needs to be said though that most researchers have stressed the need for further research recognizing the evolving and dynamic character of social media (Keles et al, 2019; Nesi et al., 2020).

This paper argues that the study of self-harming behaviors will greatly benefit from the adoption of an interdisciplinary approach that takes into consideration the latest theories and research findings from the field of media and communication. The aim is to identify the gaps in psychological research and contribute to the discussion from a communication perspective that would address some of the conceptual and methodological challenges presented. 


\section{METHODOLOGICAL CHALLENGES IN PSYCHOLOGICAL RESEARCH}

Conclusions from a major systematic review of 26 studies conducted in the period 2000-2014 (Dyson et al, 2016) identified both beneficial and detrimental effects for young people who use social media to discuss and view deliberate self-harm. Researchers were also interested in exploring the therapeutic potential of online communities. Another review of 13 studies exploring the relationship of social media and depression, anxiety and psychological distress in adolescents (Keles et al, 2019) found a "general correlation" between social media and mental health problems, "However, most authors noted that the observed relationship is too complex for straightforward statements. Few studies were designed to explore this complexity although some assessed the effect of mediating and moderating factors". (Keles et al, p. 89)

A large-scale study based on data of 10,000 14-year olds in the UK (Kelly et al. 2018) offered new insights on social media use and adolescent mental health finding that poor sleep, online harassment, poor body image and low self-esteem were strongly associated with depressive symptoms. These symptoms were higher among girls who also appeared to have a higher daily use of social media as opposed to the boys. "Time spent" or "daily use" on social media appears to be a key variable investigated in several studies, although researchers acknowledge the pitfalls of measuring this variable (Riehm et al.,2019)

A recent meta-analysis based on 61 eligible studies focusing on social media use and selfinjurious thoughts and behaviors (Nesi et al. 2020) identified a range of problematic behaviors connected to the social media, such as cyber victimization, exposure to and generation of SITBrelated content, addictive use, and sexting. Most studies suggested medium effects, while negative social media behaviors were associated to cyberbullying, exposure to harmful content, and excessive media use. Studies have also found positive social media effects as tools of social support through networks of friends and helping those at risk to access mental health resources (Goodyear \& Armour, 2019; Lavis \& Winter 2020).

Several studies are platform- specific or comparative of social media platforms, focusing primarily on the thematic analysis of different forms of content and their connection to selfharm behaviors. For example, based on the fact that pictures of non-suicidal self- injury (NSSI) such as self-cutting is frequently posted on Instagram, it was argued that social reinforcement might play a role in posting those images and policy recommendations to social media platforms to regulate their content were deemed necessary (Brown et al, 2017). Following a highly publicized suicide of a young woman in the UK associated to exposure to graphic harmful social media content, there was a public outcry and a call from public health authorities to social media platforms to regulate their content and block this type of imagery (BBC, 2019).

The focus of studies on social media content is based on research suggesting that direct exposure to both suicidal behaviors and acts of self-harm through social media may increase those behaviors, especially in more vulnerable individuals. The "blue whale challenge" is a clear example of social media content that encourages teenagers and young adults to engage in selfharm and eventually commit suicide having a "contagion" effect (Lupariello et al., 2019). A 
study of related videos on YouTube and Twitter posts found that they may have unintentional harmful effects, but "normalizing" negative content is a real threat pointing to the importance of applying safe messaging guidelines (Khasawneh et al, 2020). The potential of a copycat influence due to exposure to graphic content (Arendt, Scherr, \& Romer, 2019) poses another serious concern.

It seems though that in the absence of a causal relationship and the presence of many mediating factors, when content is not explicitly related to an act of self- harm, researchers are divided on the issue. Some argue that, both intentional and accidental exposure to NSSI content on Instagram, may elicit emotional disturbance in some users, and this is statistically related to selfharm and suicidal behaviors (Arendt et al, 2019). While others in an analysis of images across three social media sites found no posts that actually encouraged users to self-harm and very few posts portraying self- harm as attractive (Shanahan et al. 2019). Overall, most studies suggest correlations based on repeated exposure, the contagion effect, modeling and ideation, social reinforcement and normalizing effects. On the policy side, two major themes emerge as recommendations to the industry from almost all relevant studies: first, regulation of social media content linked to harmful behaviors and second, awareness and control of time spent on social media.

It appears that a good number of the limitations and gaps reported originate in theoretical and methodological challenges that are present but they have not been identified mostly due to the complexity of moderating and mediating variables at work (Valkenburg \& Peter, 2016) as well as the dynamic and constantly evolving new media environments. In fact, current findings about moderate, indirect, and conditional effects of social media on self-harm agree with most findings of a large body of research in the media effects area. Problems arise when there is not a clear account of the moderating and mediating variables. Another type of challenge comes from the nature of social media networks themselves. For example, measuring "time spent" on social media in a static way may lead to inaccurate conclusions because social media offer both synchronous and a-synchronous access and one needs also to take into account the practice of "multitasking". It seems though that even when the amount of time spent, for example more than 3 hours per day, increases the risk for mental health problems the conclusion of what needs to be done does not only refer to setting limits to daily use of social media but it extends to recommendations such as "increasing media literacy" and "redesigning social media platforms" (Riehm et al., 2019), suggestions that point to a multifactorial problem and the complexity of an effective response strategy.

Similarly, an analysis based on "content" will be more accurate if one takes into consideration the specific affordances of each social media network, the audience dynamics, and the special characteristics of specific online communities based on different social variables. Content is certainly significant but it should not be treated in a static way, as it is co-created in a dynamic social media environment (Miller et al. 2016). 


\section{TOWARDS A SOCIAL MEDIA EFFECTS FRAMEWORK}

In an attempt to address those issues, psychological research of the social media impact on self harm will benefit immensely from a long tradition of communication research on media effects, an updated non-deterministic approach on social media "affordances" and a consideration of the role of "affect" (Hipfl, 2018; Lünenborg, \& Maier, 2018) in social media. Furthermore, research will benefit from a critical cultural perspective that considers wider issues on digital culture, online community building, and new identity formation through a digital networked self (Papacharisi, 2010). To this end, drawing from the work of Valkeburg $(2013 ; 2016)$, Valkenburg \& Peter (2013) I argue for the necessity of a "social media effects framework" which lays out the media and non-media variables at play in the media effects process incorporating at the same time the technological affordances of a dynamic and constantly evolving digital media environment.

Valkenburg \& Peter (2013a) explained that dispositional, developmental, and social context factors have a key role in the media effects process in predicting media use and influencing the way in which media content is processed as they interact with specific media properties. In other words, properties of media affect how media content is processed but the effects of this propertydriven processing are contingent upon specific dispositions, the developmental level, and social context factors of the media user. In proposing a Differential Susceptibility Media Effects Model, Valkenburg and Peter (2013a) created a comprehensive media- effects model that identifies the roles and relationships between media and non-media variables, which shed light into the complexity of the media effects process contingent upon mediating and moderating variables that may also account for what many studies reported as "small" or inconsistent effects.

Building on the same approach, Valkenburg et al. (2016), through their comprehensive systematic review of studies on media effects research, identified five key features of micro-level media effects theories in mass communication research (shown in bold) that connect the (a) media with (b) the user and (c) the types of effects which are conditional, indirect, and transactional. Taking into consideration the conditional, indirect and transactional nature of media effects a researcher will find a great variation from one young adult to another making it harder to draw general conclusions on the beneficial or harmful effects on social media on the young. This also points to the need to focus on person-specific effects (Beyens et al., 2020). Consequently, based on the variables discussed above, one can examine specific groups or individuals who are at a higher risk of being affected in an effort to promote targeted prevention or intervention by the medical community. 


\section{Table 1.}

Framework of analysis based on Valkenburg et al. (2016)
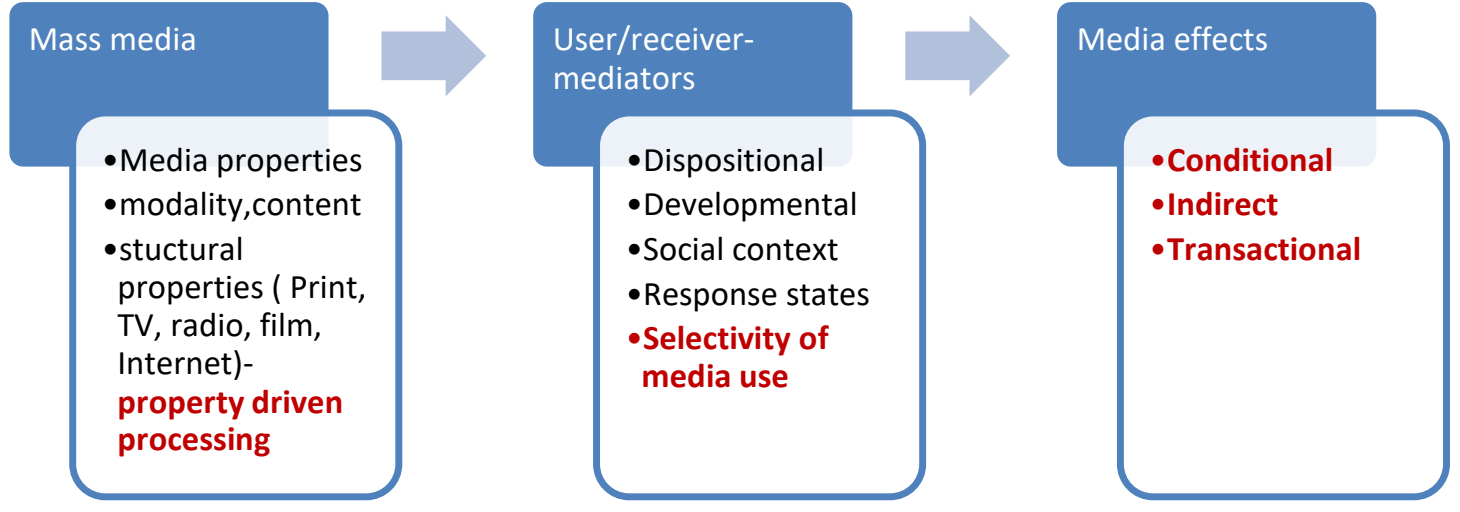

The analytical rigor of this model is based on the fact that the type of media effects, in our case social media linked to self-harm, are related to and/or moderated and mediated by a number of variables the researcher has to take into consideration. The three main components of the diagram examine the technological properties of the media, the dispositional, developmental and response states of the users/producers and the types of effects which most findings suggest they are conditional, indirect and transactional. Since most media effects are conditional and indirect, it can be hard to identify them unless the mediating variables can be measured. For example, in the case of self-harm it would be important to consider different response states such as cognitive, emotional, excitative, as part of the mental processes of media use which can influence message processing on the part of the user. Consequently, high response states may produce stronger and long-lasting effects which in turn may be connected to harmful behaviors.

Overall, this model allows to consider the interplay of individual, societal, and technological parameters and raise questions at both the micro and macro level. Given the indirect and conditional nature of effects, psychological research can focus on who would be the ones to study based on predispositions and clinical definitions of mental disorders and self-harming behaviors. Communication research, on the other hand, can study the phenomenon at both the technological/media level and the broader digital culture level. 
If we are looking for more generalized trends affecting increasing numbers of young people, one needs to go deeper and examine the following research questions:

- the specific technological affordances of social media and to what extent and under which conditions they make harmful behaviors possible or they produce a "normalizing effect"

- the specific characteristics of online communities and their connection to harmful behaviors

- the relationship between online and offline behavior when the boundaries are increasingly blurred

- the broader socio-cultural transformation through a wide spread digital culture and the new digital/networked identities as parameters contributing to mental health issues

\section{A TECHNOLOGICAL AFFORDANCES FRAMEWORK}

To further enhance our understanding of the function and appeal of social media, a growing body of academic literature on "technological affordances" provides additional analytical tools to consider in the effort to build a more comprehensive media effects framework for the analysis of this phenomenon. In that direction, the "Mechanisms and Conditions model" proposed by Davis (2020), will allow us to enhance our understanding of the property driven processing through an updated model of technological affordances. This model does not derive from the media effects tradition in communication research but it can certainly broaden our perspective on "how" social media affordances afford "for whom" and "under what conditions" and how this new understanding can be applied to the examination of issues related to social media effects regarding self-harm. Since "Affordances are how objects shape action for socially situated subjects" (Davis, 2020, p.6) it would be useful to learn from a Science and Technology Studies perspective where materiality and human agency are always connected. In the operationalizing framework for the analysis of affordances below (Table 2) one can see the communication process connecting all components: the mechanisms (how they afford), under what circumstances, for whom (users/audiences) and with what outcomes. Although some elements discussed here appear in the previous model, this particular approach allows for a political and normative focus to the question of social media and the link to self-harm and mental wellbeing. If mechanisms and conditions are connected to negative outcomes, one can make a stronger case for re-design and develop mitigating strategies: "Demarcating the conditions under which technical systems request, demand, encourage, discourage, refuse, and allow not only identifies the politics and values in technical systems but also lays the groundwork for intentional (re)design" (Davis, 2020, p.20).

For example, when examining user behavior in the context of a specific social media network, content is of primary importance. However, it is equally important to understand how those platforms encourage or discourage, refuse or allow as a response to user-initiated action. These 
technological responses matter because they can allow or deter users' initiatives. They can also be linked to specific emotional response states, which in turn may be linked to harmful behaviors. The fact that social media dominate the emotional lives of the young points to the need for studying further the role of affect in social media, a question which is currently explored in academic research from a multidisciplinary perspective (Sampson et al., 2018). Further to that, studies (Zhao et al., 2013) have identified physical, cognitive, affective, and control functions in the affordances of social media interaction. Future research may explore the role of those functions in either triggering a self-harm incident or playing a therapeutic role in providing online support to those affected. It would be very important for researchers to examine possible therapeutic affordances in serious health conditions (Merolli et al., 2014) in the context of developing mitigating strategies to tackle those problems.

\section{Table 2.}

The Media Effects Process based on Davis (2020) Mechanisms and Conditions Framework
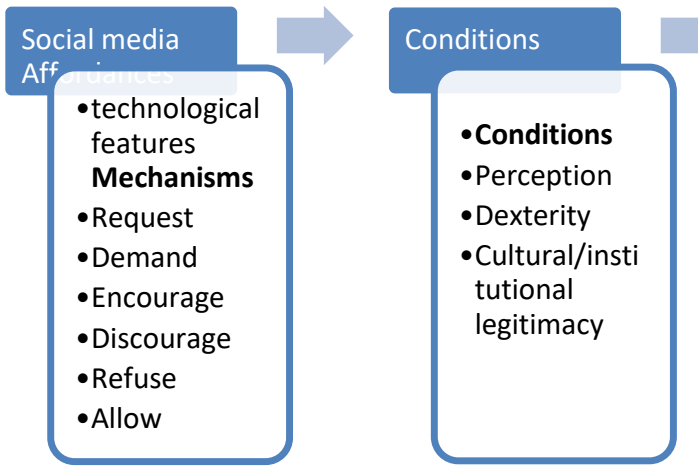

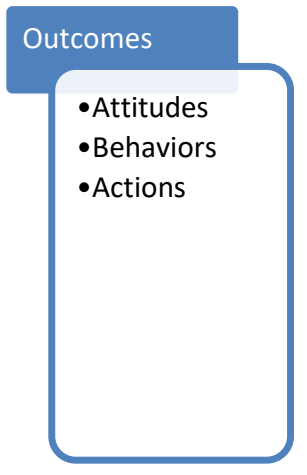




\section{A PROPOSED FRAMEWORK INTEGRATING THE TWO MODELS}

Drawing elements from both models discussed above, I propose an operationalizing framework (Table. 3) for studying the relationship between social media and self- harm that incorporates the key properties and technological affordances of social media placing them in a dynamic and multimodal context. In this table one can see the complexity of social media properties that lead to a different focus of research questions, the type of effects produced and the type of relationship to be identified. Research so far has raised questions that cover some of these variables but there are still many areas which have not been studied, indicated by a question mark. This is an effort to map areas that need to be examined utilizing analytical categories that have not been thoroughly studied. The further investigation of affective and therapeutic affordances and the types of effects they produce would enrich our knowledge on those issues (Dodemaide et al., 2019). For example, taking into consideration that self- harm relates to coping with difficult or negative emotions, the examination of platform specific effects as they relate to norms expressing emotion (Waterloo et al., 2018) may contribute to this research area. Similarly, one can examine to what extent social media can provide the mechanisms to mitigate risks (Record et al., 2019) or provide therapeutic affordances via peer support through social media interaction (Lavis et al., 2020). Furthermore, the focus on the audience helps us define the subjects of examination based on the specific affordances of "networked publics". As defined by boyd (2010) the four main affordances of social media "persistence, visibility, spreadability, and searchability" can alter and amplify social dynamics; they do not dictate the participants' behavior but the environment of their engagement and participation. This typology may extend the conversation to broader cultural effects and to what extent social media may encourage/prevent self-harming behaviors beyond those subjects who are clinically defined as self-harming. In other words, extending the research from individualized effects to wider online community cultural effects. 
Table 3. Operationalizing framework for the study of social media and self-harm

\begin{tabular}{|c|c|c|c|c|}
\hline $\begin{array}{l}\text { TECHNOLOGICAL } \\
\text { properties of social } \\
\text { media }\end{array}$ & $\begin{array}{l}\text { Media property } \\
\text { driven } \\
\text { processing }\end{array}$ & Focus on & $\begin{array}{l}\text { Self } \quad \text {-harm- } \\
\text { degree of } \\
\text { correlation }\end{array}$ & $\begin{array}{l}\text { Outcomes } \\
\text { /Effects }\end{array}$ \\
\hline Content creation & $\begin{array}{l}\text { Dynamic } \\
\text { construction/user } \\
\text { created and co- } \\
\text { created }\end{array}$ & $\begin{array}{l}\text { Type of } \\
\text { content/reception } \\
\text { Sharing/creation }\end{array}$ & $\checkmark$ & $\begin{array}{l}\text { Platform } \\
\text { Effects and } \\
\text { self-media } \\
\text { effects }\end{array}$ \\
\hline $\begin{array}{l}\text { Variability-Platform } \\
\text { specific } \\
\text { Architecture } \\
\text { affordances }\end{array}$ & $\begin{array}{l}\text { Request } \\
\text { Demand } \\
\text { Encourage } \\
\text { Discourage } \\
\text { Refuse } \\
\text { Allow }\end{array}$ & $\begin{array}{l}\text { How it affords } \\
\text { For whom }\end{array}$ & $?$ & $\begin{array}{l}\text { Platform } \\
\text { specific effects }\end{array}$ \\
\hline $\begin{array}{l}\text { Affective } \\
\text { affordances } \\
\text { Therapeutic } \\
\text { Affordances }\end{array}$ & $\begin{array}{l}\text { "affective } \\
\text { bandwidth"- } \\
\text { affective } \\
\text { computing, } \\
\text { emotional design }\end{array}$ & $\begin{array}{l}\text { Control, } \\
\text { expression, } \\
\text { management of } \\
\text { emotions/ new } \\
\text { definition of } \\
\text { intimacy }\end{array}$ & $?$ & $\begin{array}{l}\text { Media design } \\
\text { specific } \\
\text { emotional } \\
\text { effects }\end{array}$ \\
\hline $\begin{array}{l}\text { Time /frequency } \\
\text { Moment of use in } \\
\text { relation to incident }\end{array}$ & $\begin{array}{l}\text { synchronous and } \\
\text { a-synchronous } \\
\text { multitasking }\end{array}$ & $\begin{array}{l}\text { Quantity and } \\
\text { Quality of time } \\
\text { when }\end{array}$ & $\checkmark$ & $\begin{array}{l}\text { Repeated } \\
\text { exposure } \\
\text { Effects } \\
\text { Other effects }\end{array}$ \\
\hline $\begin{array}{l}\text { Intrapersonal } \\
\text { communication }\end{array}$ & $\begin{array}{l}\text { Self- } \\
\text { representation, } \\
\text { self- disclosure }\end{array}$ & $\begin{array}{l}\text { Self- esteem, } \\
\text { body image }\end{array}$ & $\checkmark$ & $\begin{array}{l}\text { Expression } \\
\text { effects }\end{array}$ \\
\hline $\begin{array}{l}\text { Interpersonal } \\
\text { communication }\end{array}$ & $\begin{array}{l}\text { Interactivity } \\
\text { properties } \\
\text { (signs, symbolic } \\
\text { interaction) }\end{array}$ & $\begin{array}{l}\text { Social } \\
\text { comparison, peer } \\
\text { influence }\end{array}$ & $\checkmark$ & $\begin{array}{l}\text { Feedback } \\
\text { effects }\end{array}$ \\
\hline Audience -dynamic & $\begin{array}{l}\text { Active } \\
\text { engagement vs. } \\
\text { passive } \\
\text { reception }\end{array}$ & $\begin{array}{l}\text { Type of } \\
\text { interaction }\end{array}$ & $?$ & $\begin{array}{l}\text { Participation } \\
\text { Effects }\end{array}$ \\
\hline $\begin{array}{l}\text { Online community } \\
\text { Support communities }\end{array}$ & $\begin{array}{l}\text { Characteristics } \\
\text { of specific } \\
\text { online } \\
\text { communities } \\
\text { Synchronous/ } \\
\text { Asynchronous } \\
\text { Closed/open }\end{array}$ & $\begin{array}{l}\text { Digital self/ new } \\
\text { identities } \\
\text { Narration } \\
\text { Self- } \\
\text { management }\end{array}$ & $?$ & $\begin{array}{l}\text { Socio- cultural } \\
\text { effects }\end{array}$ \\
\hline
\end{tabular}




\section{CONCLUSIONS}

This paper attempted to address some key theoretical challenges and methodological gaps in the study of the relationship between self- harming behaviors and social media use. The gaps identified stem primarily from a static view of the nature of social media platforms and the presence of multiple non-media variables at work. In raising those issues, the paper stressed the need for an interdisciplinary approach that will benefit from the latest communication research on social media, taking into consideration the role of the technological affordances and their effect as well as the dynamic interplay of mass and interpersonal communication in a multimodal environment of network publics. In that direction it is necessary to develop a dynamic social media effects framework which may address some of these gaps. Applying the proposed conceptual framework to the study of self-harm in future research will enhance our understanding of the role of social media in negative behaviors and identify ways of mitigating those risks. 
DOI https://doi.org/10.34097/jeicom-3-2-december2021-1

CC BY

\section{REFERENCES}

Arendt, F., Scherr, S., \& Romer, D. (2019). Effects of exposure to self-harm on social media: Evidence from a twowave panel study among young adults. New Media and Society, 21(11-12), 2422-2442. https://doi.org/10.1177/1461444819850106

BBC (2019: 7th February) Instagram vows to remove all graphic self-harm images from site. Available from: https:// www.bbc.co.uk/news/uk-47160460. [last accessed 20 March 2020]

Berryman, C., Ferguson, C. J., \& Negy, C. (2018). Social Media Use and Mental Health among Young Adults. 9535-6 Psychiatric Quarterly, 89(2), 307-314. https://doi.org/10.1007/s11126-017-

Best, P., Manktelow, R., \& Taylor, B. (2014). Online communication, social media and adolescent wellbeing: A systematic narrative review. Children and Youth Services Review,

$41,27-36$.

Beyens, I., Pouwels, J.L., van Driel, I.I. et al. (2020)The effect of social media on well-being differs from adolescent to adolescent. Sci Rep 10, 10763. https://doi.org/10.1038/s41598-020-67727-7

Biernesser, C., Sewall, C. J. R., Brent, D., Bear, T., Mair, C., \& Trauth, J. (2020). Social Media Use and Deliberate Self-Harm Among Youth: A Systematized Narrative Review. Children and Youth Services Review, 105054.

Bould H, Mars B, Moran P, Biddle L, Gunnell D (2019) Rising suicide rates among adolescents in England and Wales. Lancet 394(10193):116-117

Boyd d. (2010). Social Network Sites as Networked Publics: Affordances, Dynamics, and Implications. In Z. Papacharisi (Ed) Networked Self: Identity, Community, and Culture on Social Network Sites, pp. 39-58). Routledge, New York

Castells, M. (2009). Communication power. Oxford University Press

Children's Society (2018) Children's Society. [Online] Available from: https://www.childrenssociety.org.uk/sites/default/files/the_good_childhood_report_full_2018.pdf [last accessed 23 May 2019].

Daine, K., Hawton, K., Singaravelu, V., Stewart, A., Simkin, S., \& Montgomery, P. (2013). The power of the web: a systematic review of studies of the influence of the internet on selfharm and suicide in young people. PloS One, 8(10), e77555.

Davis, J.L. (2020). How Artifacts Afford: The Power and Politics of Everyday Things. MIT Press, Cambridge

Dodemaide, P., Joubert, L., Merolli, M., \& Hill, N. (2019). Exploring the therapeutic and nontherapeutic affordances of social media use by young adults with lived experience of self-harm or suicidal ideation: a scoping review. Cyberpsychology, Behavior, and Social Networking, 22(10), 622-633

Dyson, MP, Hartling L, Shulhan J, Chisholm A, Milne A, Sundar P, et al. (2016) A Systematic Review of Social Media Use to Discuss and View Deliberate Self-Harm Acts. PLOS ONE 11(5): e0155813. https://doi.org/10.1371/journal.pone.0155813

Hawton, K., Saunders, K., \& O’Connor, R. (2012). Selfharm and suicide in adolescents. The Lancet, 379, 23732382.

John, A., Glendenning, A. C., Marchant, A., Montgomery, P., Stewart, A., Wood, S., Lloyd, K., \& Hawton, K. (2018). Self-harm, suicidal behaviours, and cyberbullying in children and young people: Systematic review. In Journal of Medical Internet Research (Vol. 20, Issue 4). Journal of Medical Internet Research. https://doi.org/10.2196/jmir.9044 
Fung, I. C., Blankenship, E. B., Ahweyevu, J. O., Cooper, L. K., Duke, C. H., Carswell, S. L., Jackson, A. M., Jenkins, J. C., 3rd, Duncan, E. A., Liang, H., Fu, K. W., \& Tse, Z. (2020). Public Health Implications of Image-Based Social Media: A Systematic Review of Instagram, Pinterest, Tumblr, and Flickr. The Permanente journal, 24, 18.307. https://doi.org/10.7812/TPP/18.307

George M. (2019). The Importance of Social Media Content for Teens' Risks for Self-harm, Journal of Adolescent Health 65 (2019) 9e10

Hipfl, B. (2018). Affect in media and communication studies: Potentials and assemblages. Media and Communication, 6(3), 5-14.

Ilakkuvan V, Johnson A, Villanti AC, et al. (2019).Patterns of social media use and their relationship to health risks among young adults. J Adolesc Health 2019; 64:158e64.

John, A., Glendenning, A.C., Marchant, A., Montgomery, P.,Stewart, A., Wood, S., Lloyd, K., \& Hawton, K. (2018). Selfharm, suicidal behaviours, and cyberbullying in children and young people: Systematic review. Journal of Medical Internet Research, 20, e129.

Keles, B., McCrae, N., \& Grealish, A. (2020). A systematic review: the influence of social media on depression, anxiety and psychological distress in adolescents. International Journal of Adolescence and Youth, 25(1), 79-93. https://doi.org/10.1080/02673843.2019.1590851

Kelly, Y., Zilanawala, A., Booker, C., \& Sacker, A. (2019). Social media use and adolescent mental health: Findings from the UK Millennium Cohort Study. EClinicalMedicine, 4, 59-68.

Lavis A, Winter R. (2020) \#Online harms or benefits? An ethnographic analysis of the positives and negatives of peer-support around self-harm on social media. J Child Psychol Psychiatry 61(8):842-854. doi: 10.1111/jcpp.13245. Epub 2020 May 27. PMID: 32459004.

Lünenborg, M., \& Maier, T. (2018). The Turn to Affect and Emotion in Media Studies. Media and Communication, 6(3), 1-4. https://doi.org/10.17645/mac.v6i3.1732

Lupariello, F., Curti, S.M., Coppo, E., Racalbuto, S.S., \& DiVella, G. (2019). Self-harm risk among adolescents and the phenomenon of the "blue whale challenge": case series and review of the literature. Journal of Forensic Sciences, 64, 638-642.

McManus S, Gunnell D, Cooper C et al, (2019). Prevalence of non-suicidal self-harm and service contact in England, 2000-2014: repeated cross-sectional surveys of the general population. Lancet Psych 6(7):573-581

McManus, S., Gunnell, D. (2020). Trends in mental health, non-suicidal self-harm and suicide attempts in 16-24year old students and non-students in England, 2000-2014. Soc Psychiatry Psychiatr Epidemiol 55, 125-128 https://doi.org/10.1007/s00127-019-01797-5

Merolli, M., Gray, K. and Martin-Sanchez, F. (2014). Therapeutic affordances of social media: emergent themes from a global online survey of people with chronic pain. Journal of Medical Internet Research, 16(12), e284.

Morgan C, Webb RT, Carr MJ, Kontopantelis E, Green J, Chew-Graham CA, Kapur N, Ashcroft DM (2017) Incidence, clinical management, and mortality risk following self-harm among children and adolescents: cohort study in primary care. BMJ 18(359): j4351

Papacharisi Z ed. (2010) Networked Self: Identity, Community, and Culture on Social Network Sites. Routledge, New York

Record RA., Straub K., Stump N. (2019). \#Selfharm on \#Instagram: Examining User Awareness and Use of Instagram's Self-harm Reporting Tool, Health Communication, DOI: 10.1080/10410236.2019.1598738 
Journal of Education, Innovation and Communication, sponsored by the

DOI https://doi.org/10.34097/jeicom-3-2-december2021-1

Riehm KE, Feder KA, Tormohlen KN, Crum RM, Young AS, Green KM, Pacek LR, La Flair LN, Mojtabai R. (2019) Associations Between Time Spent Using Social Media and Internalizing and Externalizing Problems Among US Youth. JAMA Psychiatry. Dec 1;76(12):1266-1273. doi: 10.1001/jamapsychiatry.2019.2325. PMID: 31509167; PMCID: PMC6739732

Royal Society for Public Health (2017). Social media and young people's mental health and wellbeing. Retrieved from: https://www.rsph.org.uk/our-work/policy/social-media-and-young-people-s-mental-health-andwellbeing.html

RSPH (2017). \#StatusOfMind: Social media and young people's mental health and wellbeing. London: Royal Society for Public Health

Sampson, T., Maddison, S., \& Ellis, D. (Eds.) (2018). Affect and Social Media: Emotion, Mediation, Anxiety and Contagion. Rowman \& Littlefield International.

Shakya, H.B., \& Christakis, N.A. (2017). Association of Facebook use with compromised well-being: A longitudinal study. American Journal of Epidemiology, 185, 203-211.

Shanahan N, Brennan C, House A. (2019). Self-harm and social media: thematic analysis of images posted on three social media sites. BMJ Open ;9: e027006. doi:10.1136/ bmjopen-2018-027006

Valkenburg, P.M. \& Peter, J. (2013). The differential susceptibility to media effects model. Journal of Communication, 63, 221-243. doi: 10.1111/jcom.1202

Valkenburg, P.M. \& Peter, J. (2013). Five challenges for the future of media-effects research. International Journal of Communication, 7, 197-215. doi:1932-8036/20070238.

Valkenburg, P.M., Peter, J., \& Walther, J. B. (2016). Media effects: Theory and Research. Annual Review of Psychology, 67, 315-338. doi: 10.1146/annurev-psych-122414-033608

Valkenburg, P.M. \& Petrowski J.T. (2017). Plugged In: How Media Attract and Affect Youth. Yale University Press

Waterloo SF, Baumgartner SE, Peter J, Valkenburg PM. (2018) Norms of online expressions of emotion: Comparing Facebook, Twitter, Instagram, and WhatsApp. New Media Soc. May;20(5):1813-1831. doi: 10.1177/1461444817707349. Epub 2017 May 23. PMID: 30581358; PMCID: PMC6256717.

Zhao, Y., Liu, J., Tang, J. and Zhu, Q. (2013). Conceptualizing perceived affordances in social media interaction design. In Aslib Proceedings, 65(3), 289-303. Emerald Group Publishing Limited

This Journal Article is brought to you for free and open access by the double blind reviewed Journal of Education, Innovation and Communication, sponsored by the Communication Institute of Greece. For more information, please take a look at https://coming.gr/journal-of-education-innovation-and-communication-jeicom/ or/and email us at jeicom@coming.gr 